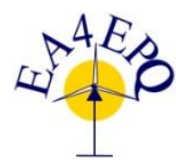

International Conference on Renewable Energies and Power Quality (ICREPQ'17)

Malaga (Spain), 4th to 6th April, 2017

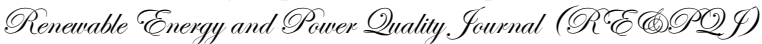

ISSN 2172-038 X, No.15 April 2017

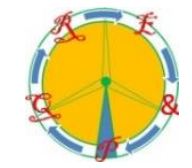

\title{
GENERATION OF ELECTRICITY USING RENEWABLE ENERGY RESOURCES
}

\author{
Saifur Rahman ${ }^{1}$, Alwadie A. ${ }^{2}$, Faizan A Khan ${ }^{3}$ \\ ${ }^{1,2}$ Department of EE, Najran University, \\ Najran-KSA-1988

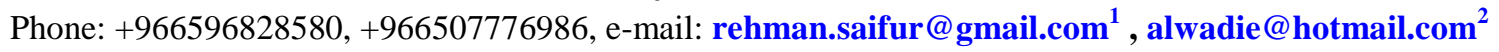 \\ ${ }^{3}$ Departmentof EE, Integral University, \\ Kursi Road, Lucknow, India-226026 \\ Phone: +919450715746, e-mail: fzn224@ gmail.com³
}

\begin{abstract}
The conventional energy resources are limited in nature, therefore it is essential to change the attention towards the other renewable energy resources. For the development of human progress energy has turn out to be an important part. Now days thrust for current renewable energy resources are leading to incessant and wide research. Wind energy, geothermal, biogas and Photovoltaic (PV)-alone are used as a single source for renewable energy. The financial features of these renewable energy tools are not fully promising. Renewable sources are under research now a days. The restriction on economic feature of various renewable sources like wind and solar PV is kept in mind and designed to develop a combined renewable energy systems. A technique is proposed in this paper which aims to improve power production by the renewable resources, like the combination of solar PV, speed breaker (roller) and sound of traffic. Using these renewable sources hybrid electricity is generated which is further utilized for street light application.
\end{abstract}

Keywords: Solar Photovoltaic (PV), Speed Breaker, Traffic Sound, Piezoelectric material.

\section{Introduction}

Energy is foundation stone of economic and prosperous development of any country. The increased requirement of energy and constrained nature of conventional energy resources leads a stable progress in renewable energy. Fast declination of fossil fuels increases the demand of alternative energy resources to accomplish the requirement. The most promising eco-friendly and fastest growing clean renewable energy source is solar energy [1].

During odd whether and in night a PV system would not be capable to produce sufficient power, some times during a sunny day power due to the difference of irradiance the load demand may not be totally satisfy by the PV system at each time. This situation is handled by integrating the PV system in association with energy storage elements and other renewable energy resources in a suitable hybrid structure.

Present Scenario of research work in the field of renewable energy sources observed a quiet change shifted the direction towards the hybrid system of lesser known and utilized renewable sources with leading renewable sources like wind and solar.

In the proposed hypotheses system is combination of lesser known and utilized renewable energy resource research on whom are in preliminary stage, are combined with solar PV system which is used as leading system and remaining are playing subsidiary role.

The study presented here gives stress to conserve the energy from different renewable energy resources in addition to solar energy resources. One of section of the whole combination based on the utilization of kinetic energy of the vehicles that has gone wasted.

Latest research opens the door to utilize the noise(sound) as an electrical energy source generated by high decibel sound. These emerging development regarding sound leads to acquire a place in the list of new renewable energy sources. Several thoughts and suggestions are given for utilization of sound as electrical generation source by using diaphragm or by piezoelectric effect.

One of the best example of change of sound energy into electrical signals is conversion of sound by diaphragm present in the microphone [2].

This Paper is organized in sequential manner Inroduction, methodology, isolated discussion of all three generation under different headings and block diagram of proposed system is given later on proposed model and conclusion are discussed. 


\section{Methodology}

Proposed thought in the whole work is based on the concept of the sharing the large requirement of load by more than one comparatively smaller load instead of giving burden on a single source (SPV). Most critical point is here that all sources are not prominent and feasible to present scenario. even leading system is also under the research. day by day new hypotheses and premises are presented by the scholar. Associated sources are less popular and continuously under the scanner of scientist.An effort is made to develop a hybrid model of generation of electricity using renewable energy resources which are less utilizes till date.

Solar energy generation is one of the leading renewable energy generation system which utilized to fulfill a fine percentage of the whole world energy demands. But, PV system not able to generate power at against conditions To overcome this problem, a PV systems are integrated with other alternative power sources .In the present research on system integration of PV by other energy sources has been proposed and combined block diagram is shown below.

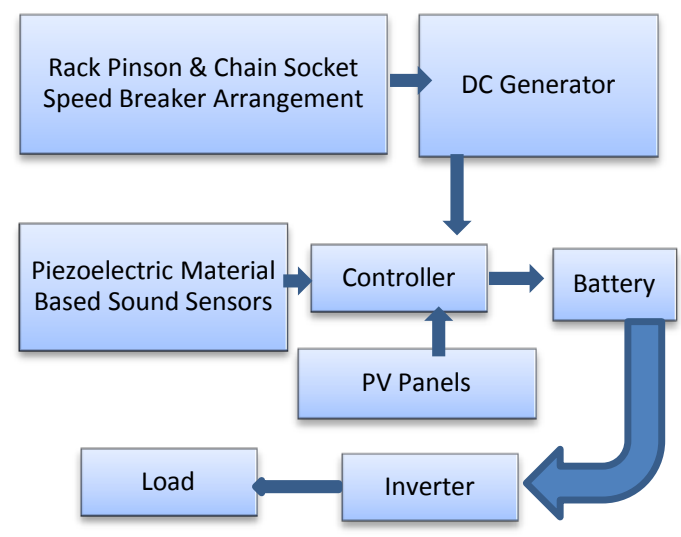

Fig1: Block Diagram For Working of proposed hybrid system

Day by day the number of vehicles passing over speed breaker on the road are increasing. The kinetic energy of vehicles moving over speed roller are confined by setting up an electro-mechanical division beneath speed breaker, known as piston/water tank assembly, which is utilized for power generation. By using different electrical devices, the generated power can be stored. In our proposed model we have used piezoelectric material and solar panel together. Both devices will generate power individually and then we will combine them together for getting better output result. In the subsequent sections, we will discuss our proposed model step by step

\section{Electricity generation From Speed Breaker}

The schematic diagram of electricity generation from speed breaker is shown in fig.1. Faraday's law of electromagnetic induction is the basic concept behind the whole phenomenon which state that, "when an armature rotates between the magnetic fields, an electro motive force(e.m.f.) is induced in it"[3].

When a vehicle passes above the dome of speed breaker by pushing it downwards, the springs connected to the dome are compressed and the rack which is linked to the extremity of the dome also moves downward in reciprocating motion.

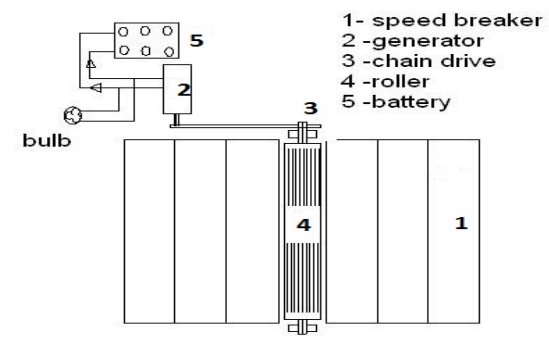

Fig2:Schematic Diagram of Electricity Generation From Speed Breaker

Reciprocating motion of rack is changed into rotating motion of gears rotary in reverse direction. A flywheel is fixed on the shaft whose job is to regulate the variation in the energy and to make the energy conversion uniform. Shafts are linked through a belt drive to the generators to rotate with specified revolution per minute(rpm), which changes the mechanical energy into electrical energy which is related to the traffic density. So, for inducing this e.m.f. the armature is connected to a long shaft to rotate the armature coil. In this way rotational kinetic energy of moving vehicles is utilized

\subsection{Mechanism involved in Electricity Generation by Speed Breaker}

The Mechanism involved used in directly generation of electricity from speed breaker are Crank shaft mechanism Roller mechanism and Rack and pinion mechanism

\section{A. Equipment Required}

The different equipment which are required in generation of electricity from speed breaker are as mentioned below:

Rack And Pinion Gears: To convert rotary motion into translatory motion, the rack and pinion gears are used.

Ball Bearings: A bearing which carries a load by placing round elements between the two pieces is known as ball bearings.

Spur Gear: A device with certain velocity ratio having a positive power transformation is known as spur gear. It is preferred for adjusting some linear misalignment.

Fly Wheel: An energy accumulator is the main function of fly wheel. It reduces the variations in speed. It saves the 
energy when the requirement is low and gives out more when the requirement is more.

Shafts: It is used as a rotary element to transmit energy from one place to another place. The rotary elements like gears and flywheels are supported by shafts. It must have more torsional stiffness and cross rigidity.

Springs: It is an elastic body whose function is to distort when loaded and to recuperate its original shape when the load is detached. It absorbs or controls energy either due to shocks or due to vibrations

Electric Dynamo: It changes mechanical energy into electrical energy based on Faraday's law of electromagnetic induction generate utilizes rotary coils of wire and magnetic fields to change mechanical rotation into a pulsing direct electric current.

\subsection{Power generated by Speed Breaker}

Let us consider,

The mass of vehicle moving over the speed breaker

$$
\begin{array}{ll}
\text { Height of speed roller } & =10 \mathrm{~cm} \\
& =0.1 \mathrm{~m} \\
\text { Work done } & =\text { Force } \times \text { Distance } \\
\text { Force } & =\text { mass of the Body } \mathrm{g} \\
& \text { (Gravitational acceleration) } \\
& =250 \mathrm{Kg} \times 9.81 \\
& =2452.5 \mathrm{~N} \\
\text { Distance travel by body } & =\text { Height of the speed breaker } \\
& =0.10 \mathrm{~m} \\
\text { Output power } & =\text { Work done } / \text { Sec } \\
& =(2452.5 \mathrm{x} 0.10) / 60 \\
& =4.0875 \mathrm{Watts} \text { (For One } \\
& \quad \text { pushing force })
\end{array}
$$

Power developed for one vehicle passing over the speed breaker (roller) for one minute $=4.0875$ watts

Power developed for one hour $=4.0875 \times 60$

$$
=245.25 \text { watts }
$$

Power developed for 24 hour $=245.25 \times 24=5.866 \mathrm{KW}$ This power is enough for illumination street lights on the roads at night time.

\subsection{Analysis of Energy generation from Speed Breaker}

The experimental analysis is done by placing the speed breaker arrangement in a trench. Vehicles travel over the speed breaker arrangement and the voltage produced is measured by a multimeter and the different observations for generation of voltage with respect to speed and generation of voltage with respect to load are plotted on accumulative graph. The graph for different parameters as Voltage generated Vs speed of vehicle and Voltage generated (Vs) Load is drawn on the basis of data obtained from practical observations displayed in confined manner on a comman scale to conclude the comparative results.
Table 1: Relation between speed and voltage generated

\begin{tabular}{|l|l|l|}
\hline S.No. & $\begin{array}{c}\text { Speed of Vehicle } \\
(\mathbf{K m} / \mathbf{h r})\end{array}$ & $\begin{array}{c}\text { Voltage } \\
\text { generated } \\
\text { (Volts) }\end{array}$ \\
\hline 1 & 10 & 8.93 \\
\hline 2 & 20 & 7.32 \\
\hline 3 & 30 & 6.05 \\
\hline 4 & 40 & 5.65 \\
\hline 5 & 50 & 4.03 \\
\hline
\end{tabular}

Table 2: Relation between Load ( man + vehicle ) and voltage generated

\begin{tabular}{|r|r|r|}
\hline Sr. No. & $\begin{array}{r}\text { Load (man \& } \\
\text { vehicle) } \mathbf{( k g s )}\end{array}$ & $\begin{array}{r}\text { Voltage } \\
\text { generated }\end{array}$ \\
\hline 1. & 360 & 8.33 \\
\hline 2. & 430 & 9.57 \\
\hline 3. & 470 & 10.44 \\
\hline 4. & 500 & 11.34 \\
\hline 5. & 550 & 11.52 \\
\hline
\end{tabular}

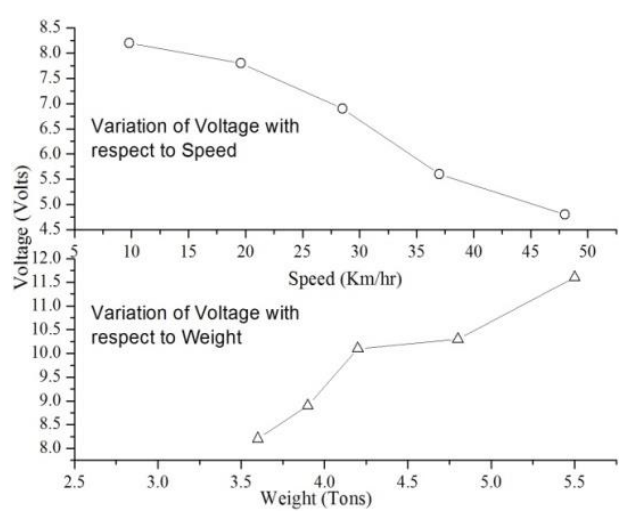

Fig 3: Graph for voltage generated under different speed of vehicles and load of man and vehicles

\section{Electrical Energy Generation From Solar PV System}

The solar PV system is a method of generating electrical energy by converting solar photon energy into direct current electricity using a solar cell or PV cell. The PV cell is the smallest unit of the solar PV system and each PV cell produces around $0.5 \mathrm{~V}$. Cells are further connected in series or/and parallel combination to form a PV array [12].

Arrangement solar PV modules vary its orientation as per the location of place where it is going to installed Solar panels are focused at solar south in the northern hemisphere and solar north in the southern hemisphere of earth [4].

The generation in the PV panel at output terminals is low voltage (DC) - usually 6 to 24 volts. It is believed that at "peak sun", $1000 \mathrm{~W} / \mathrm{m}^{2}$ of power reaches the surface of the 
earth. One hour of full sun delivers $1000 \mathrm{~W} / \mathrm{m}^{2}=1 \mathrm{~kW} / \mathrm{m}^{2}$ - representing the solar energy received in one hour on a cloudless summer day on a one-square meter surface directed towards the sun[4].

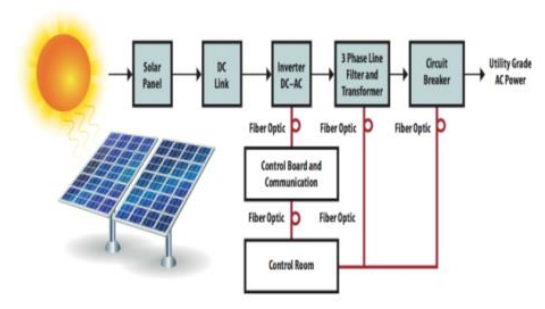

Fig. 4: Electricity Generation From Solar PV System[4]

Whole combination of the different parts of the Solar PV system are like solar panel, charge controller and battery output of system is specified in watts. Charge controller is used to monitors the battery's state-of-charge to ensure that the battery needed charge current and also ensures that the battery isn't overcharged. Battery should be able to recharge and discharge thousands of times Amp Hours (Ah). Inverter used to synchronized the generating system to the AC Load which convert DC power stored in a battery to a standard 120/240V AC electricity .

The materials used in the formation of SPV panels are thin film modules made by depositing extremely thin layers of photosensitive materials on a low-cost support such as glass, stainless steel or a polymer foil. These are manufactured from amorphous silicon (a-Si), copper indium diselenide (CIS, CIGS) and cadmium telluride (CdTe) as well as hybrid cells consisting of an amorphous silicon and a microcrystalline layer.

\section{Electrical Energy Generation by Noise (Traffic Sound)}

Generation of electricity by sound energy can be more beneficial for the human being in comparison to other sources because the sound is present everywhere in the form of noise which also forms an environmental pollution.

The concept of change of sound waves to produce energy is not a new idea. for communication purposes sound converted in the electrical signals to travel over the media.A transducer is needed to convert sound to electrical energy. These transducers are designed for the range of $20 \mathrm{~Hz}$ to 20 $\mathrm{KHz}$. This is the range of frequencies over which the transducer or microphone is considered to have a useable output [5].

The electrical current produced by a micro-phone is very small and referred to as MIC-level, this signal is usually measured in millivolts which amplified and used in combination of other renewable energy resources.

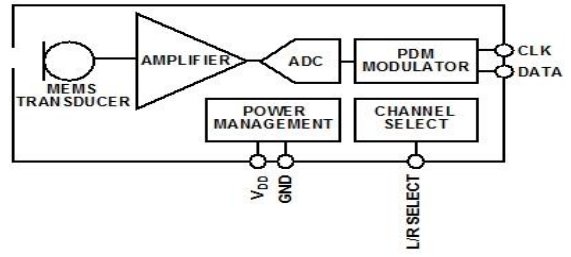

Fig5: Block Diagram Of Microphone

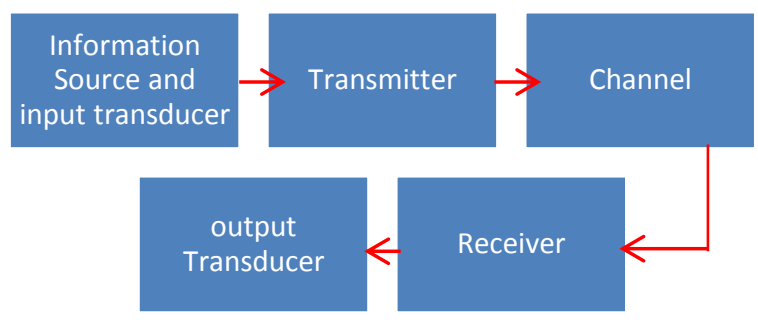

Fig.6: Block Diagram to convert sound to an electrical signal

Another aspect of electrical energy generation is by using piezoelectric effects which is based on the pressure generated by the sound, Sound is also considered as mechanical form of energy which moves in the form of wave, mechanical wave is an oscillation of pressure and this pressure is created by the sound which can be used to convert it into electric energy or other form of energy. Piezoelectric material converts mechanical strain into electric energy such as sound comes from speaker or woofers hits the diaphagram and develop compression from front to back, this movement is observed in such a manner that it could use this disturbance of sound wave to convert it into electricity across it.[6].

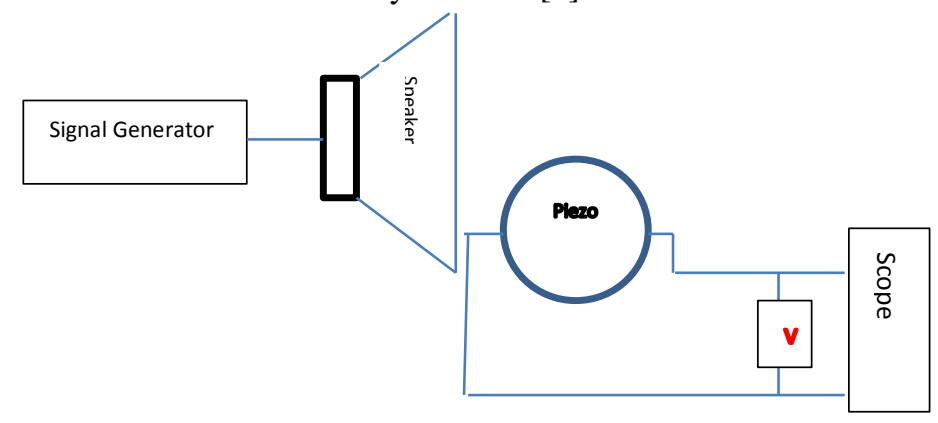

Fig 7 Energy conversion using Piezo electric material [13]

But it has certain restriction that it will be effective only at the place where high decibel of sound is available The main parts in this section lis Piezo Electric crystals which converts mechanical strain to electricity directly. Sound converted in the form of electrical energy has very small magnitude which required amplification for utilization. 


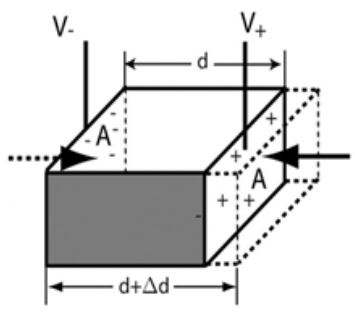

Forces change thickness and create charge

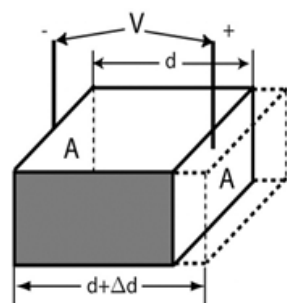

Applied voltage causes thickness changes

Fig 8 Peizo electric effect [13]

\section{Conclusion}

The generation of electricity using the weight of vehicle can be considered as an input in power generation at speed breaker using various mechanism. It is also known to us that sound is a mechanical form of energy and this can also be used to produce electrical energy using piezoelectric property of materials.

We have designed a model and collected the data of the speed and weight of the vehicle and it was found that a slower and heavier vehicle can produce much energy at speed breaker points than a lighter weight and fast moving vehicle.

The generation and operating cost of electricity produced is very low. Stored electricity can be used for other purposes. Saving the other energy resources and converting the totally waste energy in some useful work is a very good idea. This application can be helpful the government for economic purpose and give the way to utilize the wasted energy for other purposes. After some changes in the designed project and by increasing the capacity of the generator the efficiency of the whole system can be increased

\section{References}

[1] Selvaraj, R.S., Sivamadhavi, V., "Magnitude of Green House Effect and the contribution of Carbon di oxide," Recent Advances in Space Technology Services and Climate Change (RSTSCC), 13-15 Nov. 2010, no. 41 - 44, Chennai.

[2] Shakun Srivastava, Ankit asthana, "produce electricity by the use of speed breakers," Journal of Engineering Research and Studies, Vol.2, No.1 April-Jun 2011.

[3] Nahidul Hoque Samrat, Norhafizan Ahmad, Imtiaz Ahmed Choudhury, Zahari Taha "Technical Study of a Standalone Photovoltaic-Wind Energy Based Hybrid Power Supply Systems for Island Electrification in Malaysia" RESEARCH ARTICLE PLOSONE|DOI:10.1371/journal.pone.0130678 June 29, 2015.

[4] Swati Negi1 and Lini Mathew2 "Hybrid Renewable Energy System: A Review" International Journal of Electronic and

Electrical Engineering.ISSN 0974-2174, Volume 7, Number 5 (2014), pp. 535-542.

[5] Mukherje, D., Chakrabarti, S., Non-conventional power plants, New Delhi, 2005.

[6] Martin Russ, "Sound Synthesis and Sampling", 3rd vol. 2. Focal press, Abingdom, Oxon, 2008.

[7] Benoît Robyns, Arnaud Davigny, Bruno François, Antoine Henneton, Jonathan Sprooten, "Electricity Production from Renewables Energies", 1st edition, vol. 1.3, Wiley publication,2012.

[8] R.A. Aziz, S.S. Cohen, H. Dubost, M.L. Klein,” Inert Gases: Potentials, Dynamics, and Energy Transfer in Doped Crystals (Springer Series in Chemical Physics)", vol. 2.3, Springer-Verlag, 2011.

[9] Alankrit Gupta, Vivek Goel, Vivek Yadav "Conversion of Sound to Electric Energy" International Journal of Scientific \& Engineering Research, Volume 5, Issue 1, January-2014 2146 ISSN 2229-5518.

[10] Yu-Ting CHEN1 and Ching-Chung CHANG" light-ning rabbit - an application of sound energy to pro-duce more electricity" APEC Youth Scientist Journal Vol. 3.

[11] Joon-Cheol Park, Yoon-Shin Kim, Dae-Joon Kang(2008)"Propagation Characteristics and Effects of Road Traffic Noise", Korean Society of Environmental Health, Vol.34, No.4, PP.311-315.

[12] Nahidul Hoque Samrat1, Norhafizan Ahmad1*, Imtiaz Ahmed Choudhury1, Zahari Taha2 Technical Study of a Standalone Photovoltaic-Wind Energy Based Hybrid Power Supply Systems for Island Electrification in Malaysia PLOS ONE | DOI:10.1371/journal.pone.0130678 June 29, 2015

[13] Alankrit Gupta, Vivek Goel, Vivek Yadav Conversion of Sound to Electric Energy International Journal of Scientific \& Engineering Research, Volume 5, Issue 1, January-2014 2148 ISSN 2229-5518

[14] M. Asim, A.Tariq \& A. Sarwar, "Simulation and Analysis of a Directly Coupled Solar PV Based Water Pumping System," Journal on Electrical Engineering, Vol.2, no.3, 2009.

[15] Dr. Abu Tariq, Mohammed Asim and Mohd.Tariq "Simulink based modeling, simulation and Performance Evaluation of an MPPT for maximum power generation on resistive load," 2nd International Conference on Environmental Science and TechnologyIPCBEE vol.6 (2011) IACSIT Press, Singapore.

[16] Mohammed Asim, Mohd Tariq, MA Mallick, Imtiaz Ashraf "An Improved Constant Voltage Based MPPT Technique for PMDC Motor", International Journal of Power Electronics and Drive Systems (IJPEDS) Vol.7, no.4, 2016. 